\title{
Integrins Modulate Relapse to Cocaine-Seeking
}

\author{
Armina Wiggins, Rachel J. Smith, Hao-Wei Shen, and Peter W. Kalivas \\ Department of Neurosciences, Medical University of South Carolina, Charleston 29425
}

Relapse to cocaine-seeking involves impairments in plasticity at glutamatergic synapses in the nucleus accumbens. Integrins are cell adhesion molecules that bind to the extracellular matrix and regulate aspects of synaptic plasticity, including glutamate receptor trafficking. To determine a role for integrins in cocaine-seeking, rats were trained to self-administer cocaine, the operant response extinguished, and cocaine-seeking induced by a conditioned cue or noncontingent cocaine injection. This cocaine self-administration protocol reduced the content of the $\beta 3$ integrin subunit in postsynaptic density of the accumbens core at $24 \mathrm{~h}$ after the last self-administration session. However, after 3 weeks of forced abstinence plus extinction training, the level of $\beta 3$ was elevated and was further regulated over 120 min during cocaine-induced drug-seeking. A small peptide ligand [arginine-glycine-aspartate (RGD)] that mimics extracellular matrix protein binding to integrins was microinjected into the accumbens core during self-administration or extinction training, or just before cocaine-reinstated drug seeking. The daily RGD injections during self-administration or just before a reinstatement session inhibited cocaine-induced drug-seeking, while RGD microinjection during extinction training was without consequence on reinstated cocaine-seeking. Daily RGD during self-administration also prevented the enduring changes in $\beta 3$ levels. Finally, reduced surface expression of the GluR2 subunit of the AMPA receptor is associated with cocaine-seeking, and daily RGD microinjections during selfadministration training normalized the surface expression of GluR2. Together, these data indicate that the regulation integrins may contribute to cocaine-reinstated drug-seeking, in part by promoting reduced GluR2 surface expression.

\section{Introduction}

Addiction to amphetamine-like psychostimulants, such as cocaine, is associated with enduring behavioral changes that characterize the disorder, such as vulnerability to relapse and the progressive exacerbation of the anxiety- and paranoia-provoking effects of this class of drugs (O'Brien, 2001). These enduring behavioral pathologies have been modeled in experimental animals as the reinstatement of drug seeking and the sensitization of locomotor behavior (Post and Kopanda, 1976; Shaham et al., 2003). Underlying the behavioral changes in the animal models are long-lasting alterations in glutamatergic innervation of the nucleus accumbens (Kalivas, 2009). For example, the density and diameter of dendritic spines on accumbens spiny cells are increased after chronic cocaine (Robinson and Kolb, 2004; Shen et al., 2009), and there are reduced levels of AMPA glutamate receptors containing the GluR2 subunit and increase in phosphoGluR1 after withdrawal from self-administered cocaine (Zhang et al., 2007; Anderson et al., 2008; Conrad et al., 2008).

Integrins are heterodimer transmembrane cell adhesion molecules consisting of an alpha and beta subunit (Giancotti and Ruoslahti, 1999) that play an important role in regulating actin polymerization, spine morphology, and GluR2 trafficking in primary neuronal cultures (Danen et al., 2005; Kramár et al., 2006;

\footnotetext{
Received July 26, 2011; revised Aug. 21, 2011; accepted Sept. 20, 2011.

Author contributions: A.W. and P.WK. designed research; A.W., R.J.S., and H.-W.S. performed research; A.W. and

P.W.K. analyzed data; A.W., R.J.S., H.-W.S., and P.W.K. wrote the paper.

This work was supported by NIH Grants DA003906, DA012513, and DA015369.

Correspondence should be addressed to Dr. Peter Kalivas, Department of Neurosciences, 173 Ashley Avenue, BSB 410, Charleston, SC 29425. E-mail: kalivasp@musc.edu.

DOI:10.1523/JNEUROSCI.3816-11.2011

Copyright $\odot 2011$ the authors $\quad 0270-6474 / 11 / 3116177-08 \$ 15.00 / 0$
}

Shi and Ethell, 2006). Integrins bind to different proteins in the extracellular matrix depending on the subunits comprising the heterodimer and are involved in linking intracellular signaling with changes in the extracellular matrix (van der Flier and Sonnenberg, 2001; Chan et al., 2003). Importantly, plasticity in dendritic spine morphology requires changes in both the extracellular matrix and intracellular structural proteins such as actin (Bukalo, 2008; Cingolani and Goda, 2008b; Honkura et al., 2008), posing the possibility that signaling by integrins contributes to cocaine-induced pathologies in synaptic plasticity and behavior. Supporting this possibility, suppression of integrin-linked kinase (ILK) synthesis in the accumbens prevents the development of cocaine-induced behavioral sensitization, increase in spine density, and increase in Ser845 phosphorylation of GluR1 (Chen et al., 2008, 2010).

One mechanism for experimentally modulating integrin signaling is via a small peptide [arginine-glycine-aspartate (RGD)] that mimics the motif in many extracellular matrix proteins (e.g., fibronectin, vitronectin, von Willebrand factor, trombospondin, and laminim) required for binding to the beta integrin subunits (Pierschbacher and Ruoslahti, 1984; Brown and Hogg, 1996; Ruoslahti, 1996). In primary neuron cultures, RGD-like peptides increase the amplitude of EPSCs, in part by removing GluR2containing AMPA receptors from the cell surface (Kramár et al., 2003; Chan et al., 2006; Cingolani et al., 2008). Also, RGD increases spine density and length in primary neuronal culture (Shi and Ethell, 2006; Bourgin et al., 2007). In this study, we used RGD in vivo to modulate integrin activity and examined the role of integrins in the development of cocaine-induced behavioral pathologies and the trafficking of GluR2. Of the beta subunits, $\beta 1,3$, and 8 are most abundant in brain synapses; we focused on the $\beta 1$ and $\beta 3$ subunits because these subunits regulate excitatory trans- 
mission (Chan et al., 2006; Cingolani and Goda, 2008a; Cingolani et al., 2008).

\section{Materials and Methods}

Subjects. Male rats (Sprague Dawley, 225-250 g) were purchased from Charles River Laboratories and housed one animal to a cage. Food and water were provided ad libitum and animals were kept on a $12 \mathrm{~h}$ light/ dark cycle with the light cycle starting at 6:00 A.M. All experiments were conducted in accordance with the National Institutes of Health Guidelines for the Care and Use of Laboratory Animals.

Surgical procedures. Animals were implanted with bilateral guide cannula aimed at the core subcompartment of the nucleus accumbens (NAcore) according to the atlas of Paxinos and Watson (1998) $(+1.7$ $\mathrm{mm} \mathrm{AP}, \pm 2.0 \mathrm{~mm} \mathrm{ML},-5.5 \mathrm{~mm} \mathrm{DV}$ ). In one group of animals, bilateral guide cannula were implanted $2 \mathrm{~mm}$ over the dorsal striatum $(+1.7 \mathrm{~mm}$ $\mathrm{AP}, \pm 2.0 \mathrm{~mm} \mathrm{ML},-3.5 \mathrm{~mm} \mathrm{DV}$ ). Twenty-six gauge guide cannulae were lowered into NAcore and attached to the skull via small stainless steel screws and dental acrylic. Obdurators cut to extend $2 \mathrm{~mm}$ beyond the tip of each cannula were inserted to prevent obstruction by debris. For cocaine self-administration, rats were also implanted with indwelling jugular catheters. Silicone tubing was inserted subcutaneously between the shoulder blades and exited the skin via a dermal biopsy hole. The other end of the tubing was threaded under the skin, inserted $3 \mathrm{~cm}$ into the right jugular vein, and then sutured to the vein behind a silicone ball to secure its placement.

Cocaine self-administration. Approximately 1 week after surgery, subjects began behavioral training. All self-administration experiments were conducted in standard operant chambers fitted with two retractable levers. Subjects began lever pressing for cocaine (a gift from the National Institute of Drug Abuse) reinforcement on a fixed ratio 1 schedule for reinforcement. Each press of the active lever resulted in an infusion of cocaine $(0.30 \mathrm{mg} / \mathrm{kg}$ over $4 \mathrm{~s})$, followed by a light, a tone $(4.5 \mathrm{kHz})$, and a $20 \mathrm{~s} \mathrm{time} \mathrm{out,} \mathrm{in} \mathrm{which} \mathrm{active} \mathrm{lever} \mathrm{presses} \mathrm{were} \mathrm{recorded} \mathrm{but} \mathrm{resulted} \mathrm{in}$ no scheduled consequences. Responses on the inactive lever never resulted in cocaine delivery, but were recorded throughout the course of training. Each training session ran for $2 \mathrm{~h}$. Animals were trained in the self-administration paradigm for $10 \mathrm{~d}$.

Extinction training. After $10 \mathrm{~d}$ of self-administration or yoked-saline, animals were moved to the extinction phase of the experiment. During extinction, subjects experienced $2 \mathrm{~h}$ daily training sessions, but responding on the active lever no longer resulted in an infusion of cocaine or the light and tone cue. Subjects underwent extinction training for $14 \mathrm{~d}$.

Peptide administration during cocaine self-administration. For animals receiving the peptide during self-administration, on days 3 through 10 of training, one group received daily microinjections of GRADSP control peptide (RAD) and the experimental group received daily bilateral microinjections of GRGDSP peptide (RGD) into the NAcore before the training session (see Fig. $2 \mathrm{~A}$ ) (both peptides were purchased from Calbiochem). Before injection, the obdurators were removed from the guide cannula and the microinjection cannula was inserted bilaterally to extend $2 \mathrm{~mm}$ below the end of the guide cannula. All infusions were made in a volume of $0.5 \mu \mathrm{l}$ of aCSF over $60 \mathrm{~s}$ and at a dose of $1 \mathrm{nmol} / \mathrm{side}$. After infusion, the microinjectors were left in place for $1 \mathrm{~min}$ to permit diffusion before replacing the obdurators, and all animals were placed in the operant box for a training session 10-15 min after terminating the infusion. After the last self-administration session, all animals were trained to extinguish drug-seeking behavior for $14 \mathrm{~d}$ and lever pressing was then reinstated by returning the conditioned light and tone in response to active lever pressing or by administering a noncontingent injection of cocaine (15 mg/kg i.p.). Animals were tested first for cue-induced cocaine-seeking (using the same light/tone conditioning cue paired with cocaine infusion during self-administration training). The cue-induced reinstatement session was followed by cocaine-induced reinstatement after at least $3 \mathrm{~d}$ of intervening extinction sessions.

Peptide administration during extinction training. In another experiment, RAD or RGD ( $1 \mathrm{nmol}$ ) was bilaterally microinjected daily into the NAcore $10-15 \mathrm{~min}$ before the first $8 \mathrm{~d}$ of extinction training, using the same microinjection protocol described above (see protocol in Fig. $5 \mathrm{~A}$ ). Extinction training was then continued for an additional $6 \mathrm{~d}$ (total of 14 consecutive days of extinction training) and rats were tested for cue- or cocaine-induced reinstatement of cocaine-seeking as described above.

Peptide administration during cocaine reinstatement. A final group was trained to self-administer cocaine for $10 \mathrm{~d}$ and extinguished for $14 \mathrm{~d}$ without a peptide microinjection. Animals were then microinjected with RGD or RAD into the NAcore 10-15 min before administering an acute, noncontingent cocaine injection ( $15 \mathrm{mg} / \mathrm{kg}$, i.p.), and were then placed into the operant box for a reinstatement session (see Fig. 5A). A crossover design was used such that each animal underwent two cocaineinduced reinstatement sessions with RGD and RAD given in random order in alternate sessions separated by $3 \mathrm{~d}$ of intervening extinction training. Two separate groups were used to evaluate different doses of $\mathrm{RGD}$ and RAD. One group was crossed-over with $1 \mathrm{nmol}$ of RGD and $\mathrm{RAD}$ and the other group was crossed-over with $10 \mathrm{nmol}$.

Cocaine-induced behavioral sensitization. After $7 \mathrm{~d}$ of recovery from intracranial surgery, rats were habituated to the photocell boxes for 60 $\mathrm{min}$. The next day, rats were again habituated to the chamber for $60 \mathrm{~min}$ and then administered a peptide infusion (RAD or RGD at $1 \mathrm{nmol}$ ), followed by a cocaine injection ( $15 \mathrm{mg} / \mathrm{kg}$, i.p.) 10 to $15 \mathrm{~min}$ later. Distance traveled was then monitored for $120 \mathrm{~min}$. Rats were injected with cocaine plus peptide daily for $5 \mathrm{~d}$ and locomotor activity assessed. All animals then remained in their home cages for $28 \mathrm{~d}$ without cocaine or peptide treatment, and on day 33 , animals were administered a cocaine injection ( $15 \mathrm{mg} / \mathrm{kg}$ i.p.) without peptide and locomotor activity assessed in the photocell chamber (see Fig. $4 A$ ).

Subcellular fractionation. Animals were killed by fast decapitation and the NAcore was dissected and homogenized in sucrose buffer containing protease and phosphatase inhibitors. Some animals were decapitated $24 \mathrm{~h}$ after the last cocaine self-administration session, while the remaining animals were decapitated following extinction training (time $=0)$ or after 30 or $120 \mathrm{~min}$ of cocaine-induced reinstatement. Since integrin expression is not limited to synapses (Desgrosellier and Cheresh, 2010), the NAcore tissue was subfractionated to obtain a postsynaptic density (PSD)-enriched fraction to more closely estimate cocaine's effects on synaptic integrin levels (Chen et al., 2008). Bilateral NAcore were obtained from each animal before homogenization, and each animal was evaluated independently for levels of $\beta 1$ and $\beta 3$. Subcellular fractionation was performed on the NAcore tissue to yield a PSD-enriched membrane fraction (Toda et al., 2006). This process included centrifugation of homogenized tissue in sucrose buffer at $900 \times g$ for 10 min, twice, each time collecting the supernatant. Pooled supernatant from the subsequent centrifugations was spun at $900 \times g$ once more for 6 min to remove any remaining debris. The resulting supernatant was spun for $20 \mathrm{~min}$ at $12,000 \times g$ to separate the cytosolic and membrane fractions. The supernatant was aspirated and the pellet washed twice with $4 \mathrm{~mm} \mathrm{HEPES/1} \mathrm{mM}$ EDTA. The pellet was resuspended and incubated in a $0.5 \%$ Triton $\mathrm{X}$ solution for $15 \mathrm{~min}$. Samples were centrifuged for $20 \mathrm{~min}$ at $12,000 \times \mathrm{g}$. The supernatant was collected as the extrasynaptic fraction. The resulting pellet was resuspended and incubated in a buffer containing $1 \mathrm{~mm}$ DTT, $1 \%$ deoxycholic acid, $1 \%$ Triton X, and 1\% SDS for $1 \mathrm{~h}$. Samples were centrifuged for $15 \mathrm{~min}$ at $10,000 \times g$ to yield the PSD-enriched supernatant. This fraction has been optimized for the maximal collection of cytoskeletal proteins associated with the PSD as well as the PSD itself to study their function and interaction (Fukazawa et al., 2003; Toda et al., 2003, 2006).

Biotinylation assay. Animals were killed by rapid decapitation. The NAcore was bilaterally dissected and chopped using a McIlwain tissue chopper. Tissue was not pooled between animals. Ice-cold $1 \mathrm{mg} / \mathrm{ml}$ biotin-PBS solution, $\mathrm{pH}$ 8.0, was added and the sample was incubated for $30 \mathrm{~min}$ at $4^{\circ} \mathrm{C}$ with gentle rotation. The reaction was quenched by adding ice-cold $100 \mathrm{~mm}$ glycine in PBS, pH 7.8, and then centrifuged at 10,000 $\times$ $g$ for $3 \mathrm{~min}$ at $4^{\circ} \mathrm{C}$. Samples were washed twice with ice-cold $100 \mathrm{~mm}$ glycine in PBS and spun down at 10,000 $\mathrm{g}$ for $3 \mathrm{~min}$. One percent SDS in RIPA buffer (Pierce) containing protease inhibitors (Roche) was added to samples. Samples were sonicated and incubated at $4^{\circ} \mathrm{C}$ with gentle rotation for $1 \mathrm{~h}$. After incubation, samples were centrifuged at 10,000 $\times$ $g$ for $10 \mathrm{~min}$ at $4^{\circ} \mathrm{C}$. Samples were assayed for protein concentration and the sample adjusted to ensure that all samples contained the same concentration of protein. A portion of each sample was reserved to run as the 
A
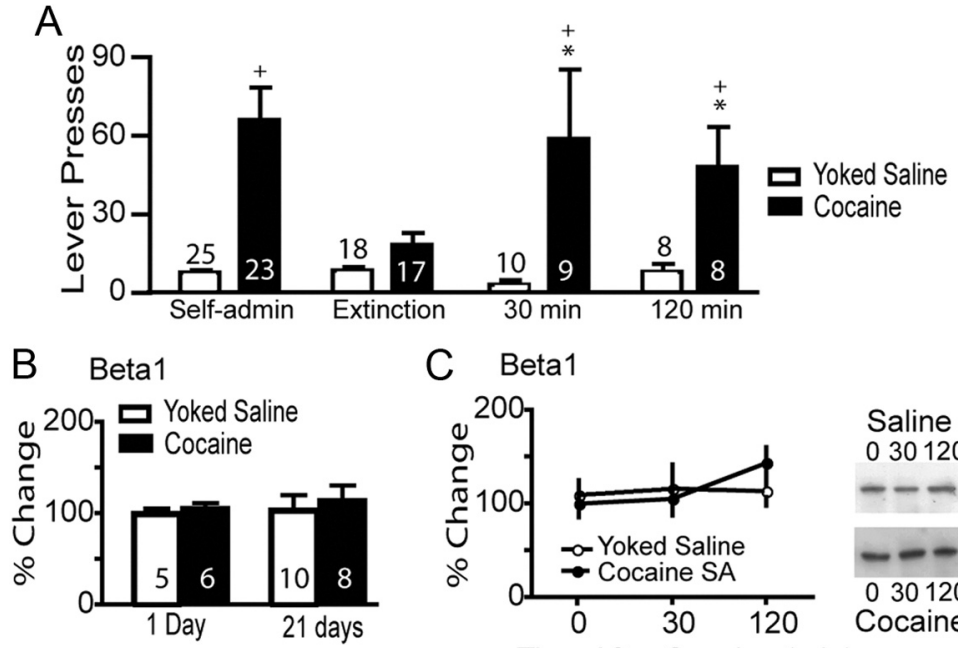

C Beta1

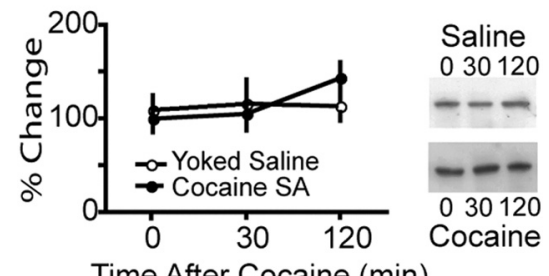

Time After Cocaine (min)
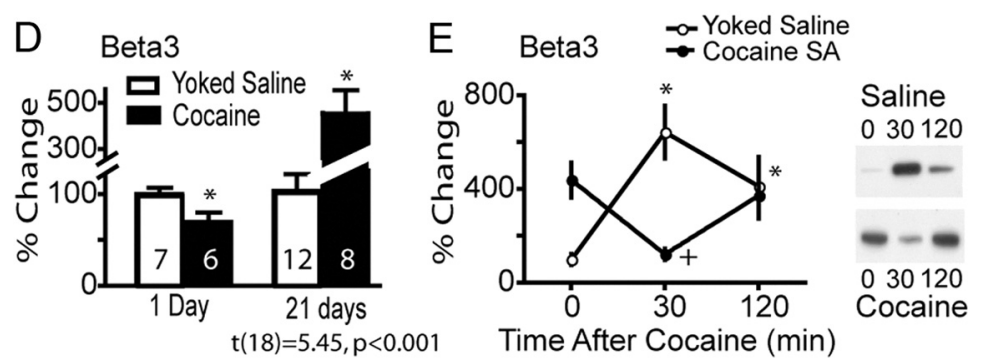

Figure 1. Cocaine self-administration regulates $\beta 3$ integrin subunit expression in the NAcore. $A$, All rats were trained to self-administer cocaine and some were extinguished and killed either after a needle stick (time $=0$ ) or 30 or 120 min after a cocaine (15 mg/kg, i.p.) injection. * $p<0.05$, compared with extinction lever pressing using a two-way ANOVA (interaction $\left.F_{(3,133)}=4.38, p=0.006\right)$ followed by a Bonferonni post hoc for multiple comparisons. ${ }^{+} p<0.05$ comparing rats trained to cocaine self-administration versus yoked-saline. $B, C$, Cocaine did not alter the levels of $\beta 1$ injection in the NAcore of any treatment group compared with yoked-saline. $\boldsymbol{D}$, At $24 \mathrm{~h}$ after the last cocaine self-administration (SA) session, the levels of $\beta 3$ in the PSD of the NAcore was lower compared with yoked-saline controls $\left(t_{(11)}=2.32, p<0.041\right)$, while the levels of $\beta 3$ were increased in the cocaine group after 3 weeks of extinction training $\left(t_{(18)}=5.45, p<0.001\right) .{ }^{*} p<0.05$. $E$, An acute cocaine injection dynamically regulated $\beta 3$ integrin in the NAcore. A two-way ANOVA revealed a significant interaction $\left(F_{(2,41)}=21.19, p<0.001, n=6-12\right)$ for each group. Lanes shown in $\boldsymbol{C}$ and $\boldsymbol{E}$ are representative of adjacent lanes out of a total 26 lanes run for each gel. ${ }^{*} p<0.05$ comparing all data to yoked-saline time $=0$ using a Bonferroni post hoc. ${ }^{+} p<0.05$, comparing 30 and 120 min to 0 min within the cocaine treatment group.

total protein fraction. High-capacity NeutrAvidin agarose resin (Thermo Scientific) was added to the remainder of the sample and the samples were incubated for $2 \mathrm{~h}$ at $4^{\circ} \mathrm{C}$ with gentle rotation. Samples were centrifuged at $10,000 \times g$ for $3 \mathrm{~min}$ at $4^{\circ} \mathrm{C}$ and the supernatant collected for the nonbiotinylated fraction. The pellets were washed with ice-cold PBS and spun down twice at $10,000 \times g$ for $3 \mathrm{~min}$. Fifty microliters of loading buffer containing $100 \mathrm{~mm}$ DTT was added and samples were heated at $80^{\circ} \mathrm{C}$ for $5 \mathrm{~min}$ on a heat block. Finally, samples were spun down at $10,000 \times g$ for $3 \mathrm{~min}$ and the supernatant collected for the biotinylated fraction.

Western blotting. Western blot analysis was performed using standard SDS PAGE techniques as described by Toda et al. (2003). All samples were reduced with $5 \mathrm{~mm}$ DTT and run on 10\% Tris glycine gels. Each gel contained 26 lanes and at least four yoked-saline control samples were run on each gel to permit later normalization to the average density of controls within each gel. Precisely $15 \mu \mathrm{g}$ of protein was loaded into each well. Protein from gels was transferred for 7 min onto PVDF membranes. Membranes were blocked for $1 \mathrm{~h}$ in a $3 \%$ milk/TBS-Tween solution and incubated in primary antibodies overnight. The next day, membranes were washed in blocking buffer for $30 \mathrm{~min}$ and incubated in the appropriate secondary antibody for $2 \mathrm{~h}$. Membranes were washed with TBST solution and water for $45 \mathrm{~min}$ and developed using Pierce Pico Supersignal chemiluminescent kit. Films were scanned and densitometry was measured by NIH ImageJ. Antibodies used for immunoblotting included mouse monoclonal antibodies against the GluR2, $\beta 3$ integrin, $\beta 1$ integrin (all from Millipore), and rabbit polyclonal antibodies against GluR1 (Abcam).

Histology. Rats were overdosed with pentobarbital (100 mg/kg, i.p.) and then perfused transcardially with $0.9 \%$ physiological saline followed by $10 \%$ formalin. Brains were removed and placed in a $10 \%$ formalin solution for at least $24 \mathrm{~h}$ before slicing. The brains were blocked and sliced in coronal sections $(100 \mu \mathrm{m})$ through the site of guide cannula implantation Brains were stained with cresyl violet to determine the location of the injection sites. Animals in which the injection sites were not in the targeted region were removed from the study.

Statistical analysis. Behavioral data and Western blots were analyzed using a two-way ANOVA followed by a Bonferroni post hoc $t$ test for multiple comparisons. If only two groups were compared, statistical significance $(p<0.05)$ was determined using a Student's $t$ test.

\section{Results \\ $\beta 3$ integrin in the PSD is regulated by cocaine self-administration}

Rats were trained to self-administer cocaine or were yoked-saline controls; those in the self-administered cocaine group pressed the active lever more often than yoked-saline controls (Fig. 1A). One group of animals was killed $24 \mathrm{~h}$ after the last selfadministration session and levels of $\beta 1$ and $\beta 3$ integrin subunits were measured in the PSD subfraction of the NAcore, as both of these subunits have been implicated in excitatory transmission (Chan et al., 2006; Cingolani and Goda, 2008a; Cingolani et al., 2008). After the last day of self-administration training, another group of rats underwent extinction training and were killed at 0,30 , or 120 min following a cocaine priming injection. All cocainetrained rats receiving a cocaine priming injection reinstated drug-seeking behavior at 30 or $120 \mathrm{~min}$ after injection (Fig. 1A). At no time after cocaine self-administration or acute cocaine-induced reinstatement were the levels of $\beta 1$ altered in the NAcore (Fig. $1 B, C$ ). In contrast, the $\beta 3$ integrin subunit was significantly reduced compared with yoked-saline controls at $24 \mathrm{~h}$ after the last self-administration session. However, after 3 weeks of forced abstinence plus extinction training, $\beta 3$ levels were markedly elevated $(>400 \%)$ in the cocaine-trained animals (Fig. $1 D)$. After a cocaine priming injection in yoked-saline rats, $\beta 3$ integrin levels significantly increased at $30 \mathrm{~min}$ and decreased back toward baseline by $120 \mathrm{~min}$ (Fig. $1 E$ ). In cocaine-seeking rats, $\beta 3$ integrin expression decreased from elevated baseline levels at $30 \mathrm{~min}$ after a cocaine injection and was not significantly different from $\beta 3$ integrin expression in yoked-saline rats at baseline (Fig. $1 E$ ). $\beta 3$ integrin protein expression returned to precocaine injection levels by 120 min after injection.

\section{RGD during cocaine self-administration inhibited cocaine-reinstated drug-seeking}

Because the first experiment showed that cocaine selfadministration and cocaine-reinstated drug-seeking dynami- 
cally regulated the levels of the $\beta 3$ integrin subunit, we examined whether modulating integrin binding to the extracellular matrix might affect cocaine self-administration, extinction, or reinstated drug-seeking. The RGD peptide mimics extracellular matrix binding to integrins (see Introduction, above), and either RGD or the control peptide RAD was administered during these epochs of cocaine training. Figure $2 \mathrm{~A}$ shows the treatment protocol used for peptide administration into the NAcore during cocaine self-administration, where a peptide microinjection was made before each session on the last $8 \mathrm{~d}$ of training. Both the control and experimental groups responded similarly on the active lever for cocaine and received a similar number of cocaine infusions (Fig. 2B). These groups also did not differ in the level of extinction responding (Fig. 2C). However, after a cocaine priming injection (15 mg/kg i.p.) to reinstate active lever pressing, animals that received RGD during self-administration responded significantly less than control animals that were microinjected with RAD during selfadministration, and were not significantly different from the average level of extinguished lever presses (Fig. 2D). Both groups reinstated when presented with cocaineassociated cues, and there was no difference in the response to cue-induced reinstatement of drug-seeking behavior between the RAD and RGD treatment groups (Fig. 2D). While eight daily injections produced a significant glial scar due to repeated mechanical disruption, the neuropil adjacent to the injection cannula scar contained spiny neurons and did not appear damaged (Fig. 2E).

To control for a site-specific action in the NAcore, a set of animals were prepared with microinjection cannula $2 \mathrm{~mm}$ dorsal to the NAcore in the dorsal striatum. As in the NAcore (Fig. 2), rats were microinjected with RAD or RGD into the dorsal striatum during the last $8 \mathrm{~d}$ of cocaine selfadministration training (Fig. 3A). Selfadministration measured as either active lever presses or cocaine infusions was not altered by daily microinjections of RGD or $\mathrm{RAD}$ peptide into the dorsal striatum (Fig.

$3 A$ ). Rats from both groups extinguished at the same rate and did not differ in active lever responding (Fig. 3B). After $14 \mathrm{~d}$ of extinction training, the rats were re-exposed to cocaine infusion-associated light and tone conditioned cues or given a cocaine priming injection. There was no difference in reinstated cocaine-seeking behavior between the RGD and RAD groups after either cues or noncontingent cocaine administration (Fig. 3C).

\section{RGD inhibited the development of enduring behavioral sensitization}

To determine whether the inhibitory effect of RGD in the NAcore was specific for the cocaine self-administration procedure or
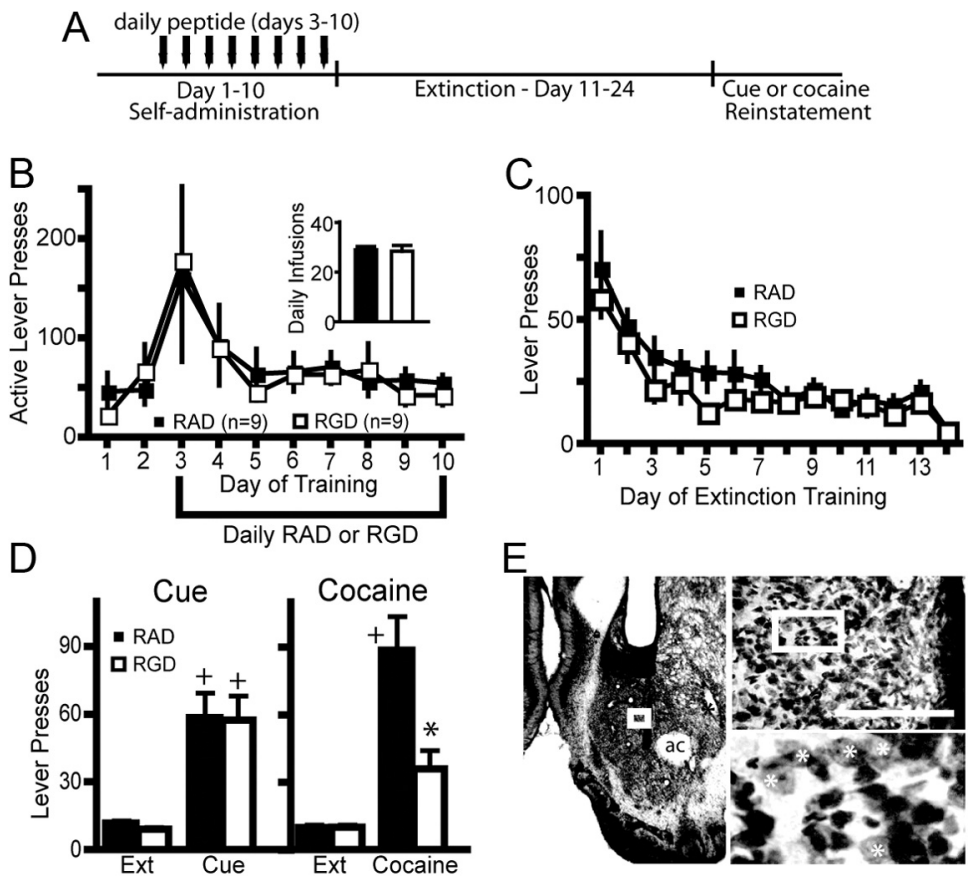

Figure 2. Modulation of integrin signaling in the NAcore during cocaine self-administration attenuates cocaine-reinstated lever pressing. $\boldsymbol{A}$, Experimental time line of peptide and cocaine administration, followed by extinction and reinstatement testing compared with RAD microinjected controls. C, RGD administration during cocaine self-administration had no effect on subsequent lever pressing during extinction training. $D, R G D$ administration attenuated cocaine-primed reinstatement but not cue-induced interaction $\left(F_{(3,48)}=5.31, p=0.003\right)$ and main effects of peptide $\left(F_{(1,48)}=4.97, p=0.041\right)$ and session $\left(F_{(3,48)}=26.49, p<\right.$ 0.001). Ext, Extinction. $\boldsymbol{E}$, Micrograph of an animal microinjected with daily RGD. Note cannula placement into the NAcore and a lack show the location of the next higher-power micrograph. Scale bar, $200 \mu \mathrm{m}$. ac, Anterior commissure. White asterisk indicates
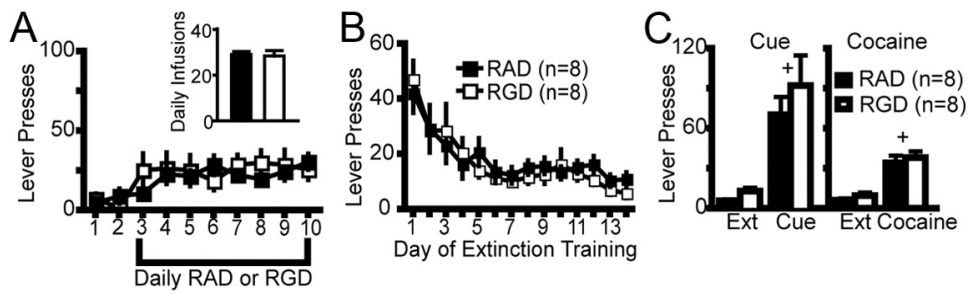

Figure 3. RGD microinjection into the dorsal striatum during cocaine self-administration did not affect cocaine selfadministration, extinction, or reinstated cocaine-seeking. $\boldsymbol{A}, \mathrm{RGD}$ administered into the dorsal striatum had no effect on cocaine active lever pressing. $\boldsymbol{B}, \mathrm{RGD}$ did not alter extinction lever pressing. $\boldsymbol{C}, \mathrm{RGD}$ and RAD treatments resulted in equivalent cue- and cocaine-induced reinstated drug-seeking. A two-way ANOVA revealed significant cue-induced $\left(F_{(1,14)}=29.43, p<0.001\right)$ and cocaine-induced $\left(F_{(1,14)}=62.10, p<0.001\right)$ reinstatement, but no effect of RGD or interaction between reinstated behavior and RGD. ${ }^{+} p<0.05$ comparing reinstatement sessions with extinction lever pressing using a Bonferroni post hoc $t$ test.

could also inhibit another form of cocaine-induced behavioral plasticity, animals were injected daily with noncontingent cocaine to induce behavioral sensitization (Kalivas and Stewart, 1991). Figure $4 A$ shows the treatment regimen of systemic noncontingent cocaine administration and peptide microinjection into the NAcore. The administration of RGD into the NAcore before the first cocaine injection did not alter locomotor activity compared with microinjection of the control RAD peptide (Fig. $4 B$ ). Over the course of the $5 \mathrm{~d}$ of chronic peptide pretreatment and cocaine administration, the total distance traveled was significantly elevated in both peptide-treated groups, indicating no effect on the development of sensitization, akin to the lack of 
A Daily cocaine and peptide Washout Day 33
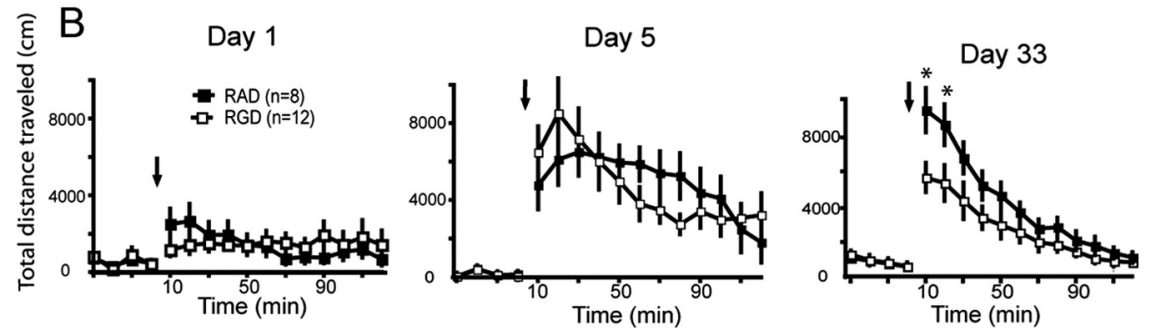

Figure 4. Cocaine-induced sensitization was attenuated in rats treated daily with RGD into the NAcore. $\boldsymbol{A}$, Experimental time line of peptide and cocaine administration, and behavioral testing. $\boldsymbol{B}$, Distance traveled in RGD- $(n=8)$ or RAD- $(n=$ 12) microinjected rats after the first cocaine injection on the first day of cocaine administration (day 1$)$, on the last daily cocaine injection (day 5), and $28 \mathrm{~d}$ after the last cocaine injection (day 33). Arrow indicates the time of cocaine (15 mg/ $\mathrm{kg}$, i.p.) administration. A two-way ANOVA with repeated measures over time revealed significant effects on day 33 only, including for treatment $\left(F_{(1,240)}=31.42, p<0.001\right)$ and time $\left(F_{(15,240)}=29.71, p<0.001\right)$, as well as an interaction between treatment and time $\left(F_{(15,240)}=2.04, p<0.001\right)$. ${ }^{*} p<0.05$ comparing RAD to RGD using a post hoc Bonferonni $t$ test.
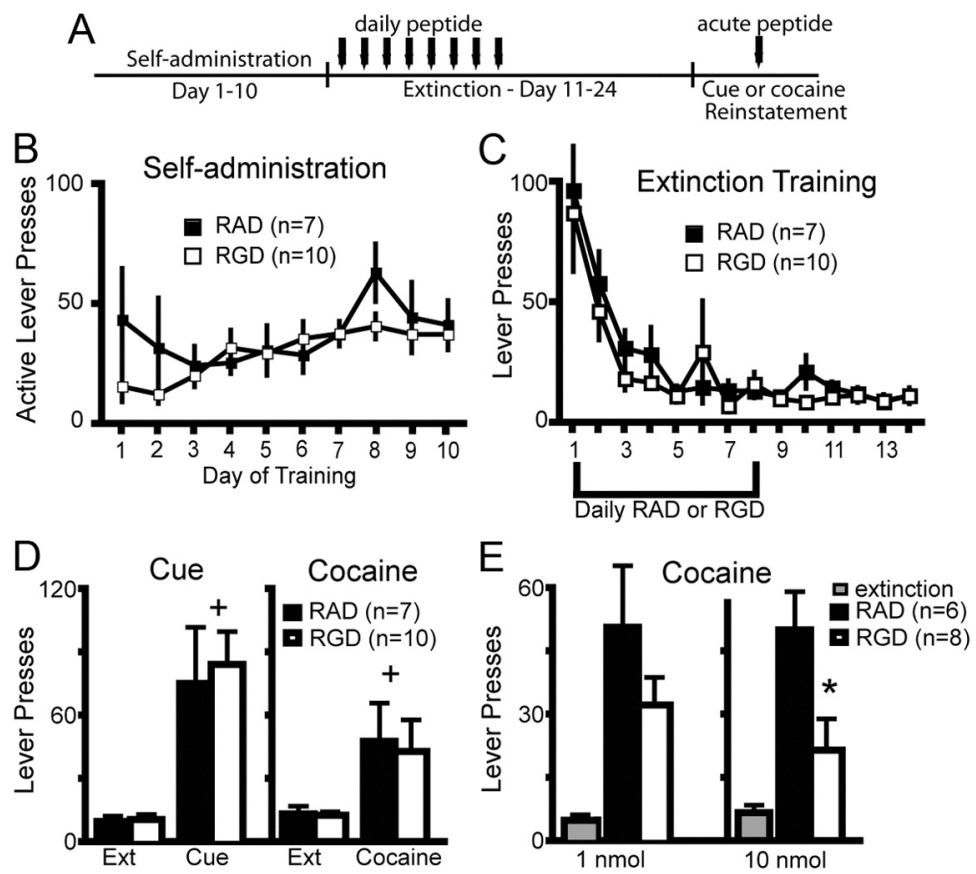

Figure 5. RGD into the NAcore during extinction training did not alter extinction or reinstated lever pressing, but acute RGD reduced cocaine-reinstated lever pressing. $A$, Treatment protocol for daily peptide injection, the first $8 \mathrm{~d}$ of extinction training, or acute peptide microinjected 10 min before an acute cocaine priming injection. $\boldsymbol{B}$, Active lever pressing and cocaine intake were equivalent in animals receiving RAD and RGD during extinction training (see inset for average of the last $3 \mathrm{~d}$ of cocaine intake). $\boldsymbol{C}$, Rats microinjected with RGD or RAD during extinction did not differ in extinction lever pressing. $D$, RGD during extinction (Ext) did not alter reinstated cocaine-seeking. A two-way ANOVA revealed significant differences between extinction lever pressing and lever pressing after cue $\left(F_{(1,15)}=23.53, p<0.001\right)$ or cocaine $\left(F_{(1,15)}=6.96, p=0.019\right)$, but no differences between RGD and RAD. ${ }^{+} p<0.05$, comparing cocaine and cue-induced reinstated lever pressing with extinction pressing using a Bonferroni post hoc test. $\boldsymbol{E}$, Microinjection of the highest dose of RGD ( $10 \mathrm{nmol} / \mathrm{side}$ ) reduced cocaine-induced reinstated lever pressing compared with RAD treatment (paired Student's $t$ test, $t_{(5)}=3.83, p=0.012$ ), while the lower dose ( $1 \mathrm{nmol} / \mathrm{side}$ ) was without significant effect. ${ }^{*} p<0.05$, comparing RAD to RGD.

effect by RGD on cocaine self-administration (Fig. 2). However, following $28 \mathrm{~d}$ of drug washout in the home cage, when the sensitized locomotor response was reinstated with an acute injection of cocaine, the locomotor response was significantly less during the first $20 \mathrm{~min}$ after cocaine in rats treated during daily cocaine administration with RGD peptide compared with RAD-treated rats (Fig. 4B). Importantly, both groups showed similar behavior during the $1 \mathrm{~h}$ habituation period before cocaine administration, indicating no enduring effect of RGD microinjection on pharmacologically unstimulated locomotor activity.

Daily RGD during extinction training did not affect reinstated

cocaine-seeking

To determine whether daily RGD needed to be given during cocaine self-administration to inhibit cocaine-induced reinstatement, animals were pretreated with daily peptide on the first $8 \mathrm{~d}$ of extinction training (Fig. $5 A$ ). Animals were divided into RGD and RAD treatment groups such that levels of cocaine self-administration were equivalent (Fig. 5B). Extinction responding was not altered after peptide administration (Fig. 5C), and both peptide treatment groups demonstrated equivalent cueand cocaine-induced reinstatement of drug-seeking (Fig. 5D).

\section{Acute RGD reduced cocaine-induced reinstatement}

Since the acute administration of cocaine to reinstate drug-seeking was associated with dynamic changes in $\beta 3$ (Fig. $1 E$ ), it was of interest to determine whether modulating $\beta$ integrins with RGD just before a reinstatement session also altered reinstated behavior. Two doses of RGD or RAD (1 or $10 \mathrm{nmol}$ ) were microinjected into separate groups of animals before administering a cocaine priming injection to reinstate lever pressing. A cross-over design was used so that each animal was injected with same dose of RGD or RAD. Peptide microinjections were not made during self-administration or extinction training. Figure $5 E$ shows that the highest dose of RGD significantly reduced cocainereinstated lever pressing.

\section{Daily RGD during self-administration prevents the enduring elevation in $\beta 3$ integrin subunit}

Daily RGD microinjection during selfadministration attenuated cocaine-induced reinstated drug-seeking (for treatment protocol, see Fig. $2 \mathrm{~A}$ ). Figure $6 \mathrm{~A}$ shows that this peptide treatment also reversed the increase in baseline $\beta 3$ integrin subunit expression seen in the NAcore after cocaine self-administration. Thus, $\beta 3$ was significantly elevated in the RAD group but not the RGD group in cocaine versus yoked-saline animals (Fig. 6A). $\beta 1$ integrin expression was not altered by RGD in either the yoked-saline or control groups (Fig. $6 A$ ).

\section{Integrins regulate GluR2 surface expression}

GluR2 surface expression is regulated both by withdrawal from cocaine self-administration and in cell culture by RGD modulation of 

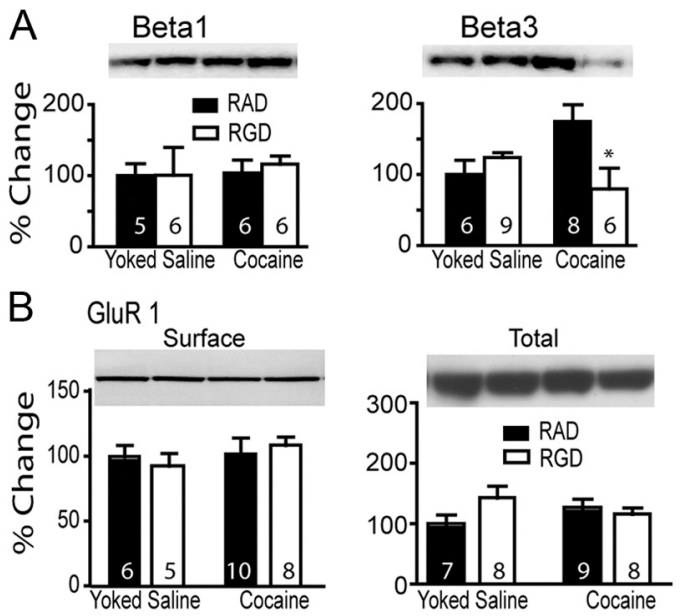

C GluR 2
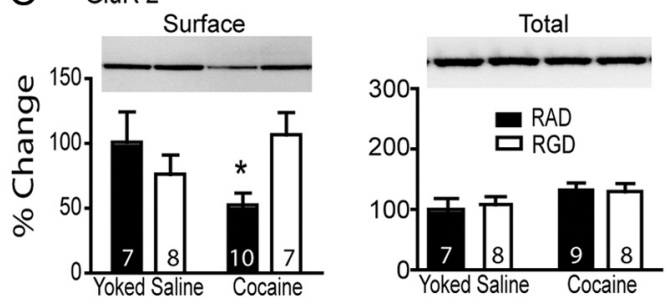

Figure 6. RGD normalized the increase in $\beta 3$ expression after 3 weeks of cocaine washout and restored cocaine-induced decrease in GluR2 surface expression. Lanes shown in all panels are representative of adjacent lanes out of a total 26 lanes run for each gel. $A$, RGD treatment did not affect basal $\beta 1$ subunit expression, but basal $\beta 3$ subunit expression was normalized by administering RGD during cocaine self-administration. A two-way ANOVA on $\beta 3$ revealed a significant interaction $\left(F_{(1,25)}=\right.$ $5.33, p=0.030)$. $\boldsymbol{B}$, No treatment affected GluR1 surface expression or total protein. $\boldsymbol{C}$, GluR2 surface expression was reduced by cocaine training in RAD animals and normalized by RGD. A two-way ANOVA for the GluR2 data revealed a significant interaction $\left(F_{(1,28)}=6.02, p=0.021\right) .{ }^{*} p<0.05$, comparing RAD to RGD within each treatment group using a Bonferroni post hoc.

$\beta$ integrins (Cingolani et al., 2008). Moreover, the reduction of surface GluR2 by cocaine is correlated with the intensity of the reinstated behavior (Conrad et al., 2008). To determine whether RGD given during self-administration might alter the increase in GluR2 produced after forced abstinence plus extinction from self-administered cocaine, rats were treated with RGD or RAD during cocaine self-administration (Fig. 1A). After 2 weeks of extinction training, the NAcore was dissected and a biotinylation strategy used to estimate the level of GluR2 and GluR1 expressed on the cell surface. Neither GluR1 surface expression nor total protein content was significantly different between any of the treatment groups (Fig. 6B). However, surface expression of GluR2 was significantly decreased in cocaine-trained animals pretreated with RAD compared with RAD-treated yoked-saline animals (Fig. 6C). Also, RGD treatment during cocaine self-administration reversed the cocaineinduced reduction in GluR2 receptor expression. Accordingly, there was no difference between RGD-treated yoked-saline and cocaine subjects. In contrast to surface levels, GluR2 total protein content did not differ between treatment groups (Fig. 6C).

\section{Discussion}

These data reveal a possible mechanism for disrupting the cocaineinduced long-term neuroplasticity that is necessary for relapse to cocaine-seeking. We demonstrated that cocaine self-administration dynamically altered the level of the $\beta 3$ integrin subunit in the nucleus accumbens. By microinjecting, during cocaine self-administration, a peptide that mimics the RGD motif used by many extracellular ma- trix proteins to bind to integrins, it was possible to prevent these changes in $\beta 3$ integrin levels, as well as to prevent cocaine-induced reinstated lever pressing. Also, reduced surface expression of GluR2 in the accumbens has been associated with the intensity of relapse in an animal model of context-induced relapse (Conrad et al., 2008; Famous et al., 2008), and modulating integrins with RGD prevented the reduction in surface GluR2 elicited by cocaine self-administration. While the dynamic regulation of $\beta 3$ levels by cocaine and the normalization of these levels by RGD supports an interaction between RGD microinjection and integrin heterodimers containing the $\beta 3$ subunit, RGD binds other integrin subunits in addition to $\beta 3$ (Desgrosellier and Cheresh, 2010). Thus, it is possible that RGD action on other integrins contributes toward inhibiting cocaine-seeking.

Integrins are regulators of cell morphology and provide a conduit for signaling between the extracellular matrix and the actin cytoskeleton (Hannigan et al., 2005; Kramár et al., 2006). Accordingly, integrins have been shown to regulate synaptic and dendritic morphology, in particular the levels of key postsynaptic proteins, such as the glutamate receptor subunits GluR1 and GluR2, and PSD-95 (Kramár et al., 2006; Shi and Ethell, 2006; Morini and Becchetti, 2010). All of these proteins are altered in the accumbens by self-administered and/or daily noncontingent injections of cocaine, with increases reported in GluR1 and PSD-95, and reductions in GluR2 (Churchill et al., 1999; Yao et al., 2004; Boudreau et al., 2007; Conrad et al., 2008). Interactions between these proteins and integrins may be via ILK, which can be coimmunoprecipitated with PSD-95 and GluR1 (Chen et al., 2010). ILK is a serine/threonine protein kinase that acts as a proximal intracellular receptor kinase for extracellular matrix binding to $\beta$ integrins (Dedhar, 2000; Dobreva et al., 2008). Akin to daily RGD injections, suppression of ILK in the NAcore via a viral siRNA strategy inhibits the development of locomotor sensitization to cocaine (Chen et al., 2008). Also, siRNA downregulation of ILK in the NAcore normalizes the increases in PSD-95 and phospho-Ser ${ }^{845}$ GluR1 that are associated with daily noncontingent cocaine administration (Chen et al., 2010). Another signaling pathway related to both cocaine behavior and cytoskeletal regulation of dendrite morphology is integrin regulation of a Rho inhibitory pathway involving Abelson-related gene (Arg)-tyrosine kinase and p190RhoGAP (Moresco et al., 2005; Sfakianos et al., 2007). Genetic deletion of Arg-tyrosine kinase augments cocaineinduced behavioral sensitization, probably via destabilization of synaptic contacts in orbital cortex (Gourley et al., 2009).

$\beta 3$ levels were differentially regulated by cocaine over the time course of the experimental protocol. Thus, at $24 \mathrm{~h}$ after discontinuing self-administration training, the level of $\beta 3$ in the NAcore was reduced, but after 3 weeks of extinction training, the levels were elevated. Moreover, while an acute cocaine injection in control animals temporarily elevated levels of $\beta 3$, the elevated level following extinction training in cocaine-trained subjects was temporarily reduced by an acute cocaine injection. The regulation of $\beta 3$ by daily cocaine self-administration was associated with reinstated cocaine-seeking since RGD administration during cocaine self-administration training both normalized the level of $\beta 3$ measured after extinction training in the NAcore and inhibited reinstated cocaine-seeking. Also, the fact that acute RGD administered into the NAcore before a cocaine priming injection inhibited reinstated drug-seeking poses the possibility that the temporary fall in $\beta 3$ levels during reinstatement may contribute to cocaine-seeking.

The efficacy of RGD to inhibit cocaine-reinstated drugseeking when given during cocaine self-administration indicates that the regulation of integrin signaling by cocaine selfadministration is an initial step toward developing the enduring 
neuroplasticity that underlies reinstated cocaine-seeking (Kauer and Malenka, 2007; Kalivas, 2009). Pretreatment with RGD will interfere with regulating integrins by extracellular matrix proteins, which could prevent the downstream alterations in spine morphology and AMPA receptor trafficking that are known to be modulated by both integrin signaling and daily cocaine administration (Robinson and Kolb, 2004; Shi and Ethell, 2006; Cingolani et al., 2008; Conrad et al., 2008). The idea that the effects of RGD on cocaine-reinstated behavior may arise from altering how extracellar matrix proteins interact with integrins is consistent with the observation that daily inhibition of matrix metalloproteinases, key extracellular enzymes for structurally modifying the extracellular matrix (Wang et al., 2008), inhibits the reinstatement of cocaine-seeking in a conditioned place preference model (Brown et al., 2007). It is also of interest that the involvement of metalloproteinases in regulating NMDA-dependent synaptic plasticity has been linked to $\beta$ integrin signaling (Michaluk et al., 2009), and the development cocaine-induced behavioral and synaptic plasticity depends upon intact NMDA signaling (Wolf, 1998; Mameli et al., 2009).

While RGD administration inhibited cocaine-reinstated drug seeking when microinjected during self-administration or just before reinstating lever pressing, when RGD was administered during extinction training, there was no effect on reinstated cocaine-seeking. The lack of effect by RGD administered during extinction training indicates that the neuroadaptations influenced by extinction training, including changes in various PSD proteins such as mGluR5, Homer1bc, and GluR1 (Sutton et al., 2003; Knackstedt et al., 2010), may not be affected by RGD.

Although RGD is a commonly used pharmacological tool for modulating integrin signaling, the action of RGD on integrin signaling is not easily classified as agonist or antagonist (Becchetti et al., 2010; Desgrosellier and Cheresh, 2010). Thus, while RGD inhibits interactions between integrins and extracellular matrix proteins containing the RGD binding motif, it also in part mimics the presence of these extracellular matrix proteins and can induce integrin-dependent cell signaling. Thus, it is difficult to predict a priori how RGD might affect the expression of integrins in brain PSD in terms of homeostatic upregulation or downregulation. In the present report, RGD microinjected during selfadministration prevented the enduring upregulation of $\beta 3$ integrin in the NAcore, and this was associated with the inhibition of reinstated cocaine-seeking. However, it is not known whether this resulted from RGD inhibiting the acute effects of cocaine during self-administration [i.e., the increase in $\beta 3$ seen after acute cocaine in the yoked-saline group (Fig. $1 E$ )], or prevented the development of the long-term elevation in $\beta 3$ by a different mechanism. Also, the levels of $\beta 3$ rapidly declined for at least $30 \mathrm{~min}$ after initiating cocaine reinstatement, and acute RGD pretreatment partly inhibited reinstated cocaine-seeking. Clearly, more work is needed to understand the mechanism by which RGD regulates $\beta 3$ expression and the role this plays in RGD-mediated inhibition of reinstated cocaine-seeking.

It was surprising that daily RGD treatment disrupted cocaine- but not cue-induced reinstated lever pressing. Although neuronal activity in the NAcore where RGD was microinjected is known to be necessary for both cocaine- and cue-induced reinstatement (Kalivas, 2009), these data reveal distinctions in how integrin signaling can differentially modulate two distinct reinstatement-provoking stimuli. Possible reasons for this difference include the involvement of glutamatergic afferents from the amygdala in cue-induced, and glutamatergic afferents from the prefrontal cortex in both cocaine- and cue-induced reinstatement of cocaine-seeking (Di Ciano and Everitt, 2004; Feltenstein and See, 2008). While cocaine-induced impairments in synaptic plasticity clearly occur in prefrontal synapses in the accumbens, it is not known how plasticity in amygdala afferents may affect reinstated cocaine-seeking (Goto and Grace, 2005; Martin et al., 2006; Moussawi et al., 2009). Also, a cocaine challenge involves substantially larger increases in dopamine and glutamate than does cue exposure (Duvauchelle et al., 2000; Weiss et al., 2000; Schiffer et al., 2009), and it is possible that involvement of integrins may be measurable only in conditions of high dopamine and/or glutamate release.

The present findings identify integrin signaling as a potential target for treating cocaine addiction. Importantly, because of the bidirectional nature of integrin signaling between the extracellular matrix and synaptic plasticity, finding integrin involvement in an animal model of cocaine relapse points to a number of possible pharmacological targets, some of which have been shown previously to regulate behaviors associated with chronic cocaine administration. For example, in addition to disrupting cocaine-induced reinstatement of cocaine-seeking by directly regulating integrins with RGD, inhibiting metalloproteinase regulation of the extracellular matrix reduces cocaine-conditioned place preference (Brown et al., 2007), and downregulating ILK inhibits cocaine-induced behavioral sensitization (Chen et al., 2008). Given these multiple potential targets, future studies need to consider the efficacy of protocols simultaneously targeting more than one protein involved in bidirectional integrin signaling to inhibit cocaine relapse.

\section{References}

Anderson SM, Famous KR, Sadri-Vakili G, Kumaresan V, Schmidt HD, Bass CE, Terwilliger EF, Cha JH, Pierce RC (2008) CaMKII: a biochemical bridge linking accumbens dopamine and glutamate systems in cocaine seeking. Nat Neurosci 11:344-353.

Becchetti A, Pillozzi S, Morini R, Nesti E, Arcangeli A (2010) New insights into the regulation of ion channels by integrins. Int Rev Cell Mol Biol 279:135-190.

Boudreau AC, Reimers JM, Milovanovic M, Wolf ME (2007) Cell surface AMPA receptors in the rat nucleus accumbens increase during cocaine withdrawal but internalize after cocaine challenge in association with altered activation of mitogen-activated protein kinases. J Neurosci 27:10621-10635

Bourgin C, Murai KK, Richter M, Pasquale EB (2007) The EphA4 receptor regulates dendritic spine remodeling by affecting betal-integrin signaling pathways. J Cell Biol 178:1295-1307.

Brown E, Hogg N (1996) Where the outside meets the inside: integrins as activators and targets of signal transduction cascades. Immunol Lett 54:189-193.

Brown TE, Forquer MR, Cocking DL, Jansen HT, Harding JW, Sorg BA (2007) Role of matrix metalloproteinases in the acquisition and reconsolidation of cocaine-induced conditioned place preference. Learn Mem $14: 214-223$.

Bukalo O (2008) Introduction: cell adhesion and extracellular matrix molecules in synaptic plasticity. Neuron Glia Biol 4:165-167.

Chan CS, Weeber EJ, Kurup S, Sweatt JD, Davis RL (2003) Integrin requirement for hippocampal synaptic plasticity and spatial memory. J Neurosci 23:7107-7116.

Chan CS, Weeber EJ, Zong L, Fuchs E, Sweatt JD, Davis RL (2006) Beta 1 -integrins are required for hippocampal AMPA receptor-dependent synaptic transmission, synaptic plasticity, and working memory. J Neurosci 26:223-232.

Chen Q, Xiong X, Lee TH, Liu Y, Wetsel WC, Zhang X (2008) Neural plasticity and addiction: integrin-linked kinase and cocaine behavioral sensitization. J Neurochem 107:679-689.

Chen Q, Zhu X, Zhang Y, Wetsel WC, Lee TH, Zhang X (2010) Integrin-linked kinase is involved in cocaine sensitization by regulating PSD-95 and synapsin I expression and GluR1 Ser845 phosphorylation. J Mol Neurosci 40:284-294.

Churchill L, Swanson CJ, Urbina M, Kalivas PW (1999) Repeated cocaine alters glutamate receptor subunit levels in the nucleus accumbens and ventral tegmental area of rats that develop behavioral sensitization. J Neurochem 72:2397-2403.

Cingolani LA, Goda Y (2008a) Differential involvement of beta3 integrin in 
pre- and postsynaptic forms of adaptation to chronic activity deprivation. Neuron Glia Biol 4:179-187.

Cingolani LA, Goda Y (2008b) Actin in action: the interplay between the actin cytoskeleton and synaptic efficacy. Nat Rev Neurosci 9:344-356.

Cingolani LA, Thalhammer A, Yu LM, Catalano M, Ramos T, Colicos MA, Goda Y (2008) Activity-dependent regulation of synaptic AMPA receptor composition and abundance by beta3 integrins. Neuron 58:749-762.

Conrad KL, Tseng KY, Uejima JL, Reimers JM, Heng LJ, Shaham Y, Marinelli M, Wolf ME (2008) Formation of accumbens GluR2-lacking AMPA receptors mediates incubation of cocaine craving. Nature 454:118-121.

Danen EH, van Rheenen J, Franken W, Huveneers S, Sonneveld P, Jalink K, Sonnenberg A (2005) Integrins control motile strategy through a rhocofilin pathway. J Cell Biol 169:515-526.

Dedhar S (2000) Cell-substrate interactions and signaling through ILK. Curr Opin Cell Biol 12:250-256.

Desgrosellier JS, Cheresh DA (2010) Integrins in cancer: biological implications and therapeutic opportunities. Nat Rev Cancer 10:9-22.

Di Ciano P, Everitt BJ (2004) Direct interactions between the basolateral amygdala and nucleus accumbens core underlie cocaine-seeking behavior by rats. J Neurosci 24:7167-7173.

Dobreva I, Fielding A, Foster LJ, Dedhar S (2008) Mapping the integrinlinked kinase interactome using SILAC. J Proteome Res 7:1740-1749.

Duvauchelle CL, Ikegami A, Asami S, Robens J, Kressin K, Castaneda E (2000) Effects of cocaine context on NAcc dopamine and behavioral activity after repeated intravenous cocaine administration. Brain Res 862:49-58.

Famous KR, Kumaresan V, Sadri-Vakili G, Schmidt HD, Mierke DF, Cha JH, Pierce RC (2008) Phosphorylation-dependent trafficking of GluR2containing AMPA receptors in the nucleus accumbens plays a critical role in the reinstatement of cocaine seeking. J Neurosci 28:11061-11070.

Feltenstein MW, See RE (2008) The neurocircuitry of addiction: an overview. Br J Pharmacol 154:261-274.

Fukazawa Y, Saitoh Y, Ozawa F, Ohta Y, Mizuno K, Inokuchi K (2003) Hippocampal LTP is accompanied by enhanced F-actin content within the dendritic spine that is essential for late LTP maintenance in vivo. Neuron 38:447-460.

Giancotti FG, Ruoslahti E (1999) Integrin signaling. Science 285:1028- 1032.

Goto Y, Grace AA (2005) Dopamine-dependent interactions between limbic and prefrontal cortical plasticity in the nucleus accumbens: disruption by cocaine sensitization. Neuron 47:255-266.

Gourley SL, Koleske AJ, Taylor JR (2009) Loss of dendrite stabilization by the Abl-related gene (Arg) kinase regulates behavioral flexibility and sensitivity to cocaine. Proc Natl Acad Sci U S A 106:16859-16864.

Hannigan G, Troussard AA, Dedhar S (2005) Integrin-linked kinase: a cancer therapeutic target unique among its ILK. Nat Rev Cancer 5:51-63.

Honkura N, Matsuzaki M, Noguchi J, Ellis-Davies GC, Kasai H (2008) The subspine organization of actin fibers regulates the structure and plasticity of dendritic spines. Neuron 57:719-729.

Kalivas PW (2009) The glutamate homeostasis hypothesis of addiction. Nat Rev Neurosci 10:561-572.

Kalivas PW, Stewart J (1991) Dopamine transmission in the initiation and expression of drug- and stress-induced sensitization of motor activity. Brain Res Rev 16:223-244.

Kauer JA, Malenka RC (2007) Synaptic plasticity and addiction. Nat Rev Neurosci 8:844-858.

Knackstedt LA, Moussawi K, Lalumiere R, Schwendt M, Klugmann M, Kalivas PW (2010) Extinction training after cocaine self-administration induces glutamatergic plasticity to inhibit cocaine seeking. J Neurosci 30:7984-7992.

Kramár EA, Bernard JA, Gall CM, Lynch G (2003) Integrins modulate fast excitatory transmission at hippocampal synapses. J Biol Chem 278: 10722-10730.

Kramár EA, Lin B, Rex CS, Gall CM, Lynch G (2006) Integrin-driven actin polymerization consolidates long-term potentiation. Proc Natl Acad Sci U S A 103:5579-5584.

Mameli M, Halbout B, Creton C, Engblom D, Parkitna JR, Spanagel R, Lüscher C (2009) Cocaine-evoked synaptic plasticity: persistence in the VTA triggers adaptations in the NAc. Nat Neurosci 12:1036-1041.

Martin M, Chen BT, Hopf FW, Bowers MS, Bonci A (2006) Cocaine selfadministration selectively abolishes LTD in the core of the nucleus accumbens. Nat Neurosci 9:868-869.

Michaluk P, Mikasova L, Groc L, Frischknecht R, Choquet D, Kaczmarek L (2009) Matrix metalloproteinase-9 controls NMDA receptor surface diffusion through integrin beta1 signaling. J Neurosci 29:6007-6012.
Moresco EM, Donaldson S, Williamson A, Koleske AJ (2005) Integrinmediated dendrite branch maintenance requires Abelson (Abl) family kinases. J Neurosci 25:6105-6118.

Morini R, Becchetti A (2010) Integrin receptors and ligand-gated channels. Adv Exp Med Biol 674:95-105.

Moussawi K, Pacchioni A, Moran M, Olive MF, Gass JT, Lavin A, Kalivas PW (2009) N-acetylcysteine reverses cocaine-induced metaplasticity. Nat Neurosci 12:182-189.

O’Brien C (2001) Drug addiction and drug abuse. In: The pharmacological basis of therapeutics (Hardman J, Limbird L, Gilman AG, eds), pp 621642. New York: McGraw-Hill.

Paxinos G, Watson C (1998) The rat brain in stereotaxic coordinates. New York: Academic.

Pierschbacher MD, Ruoslahti E (1984) Cell attachment activity of fibronectin can be duplicated by small synthetic fragments of the molecule. Nature 309:30-33.

Post RM, Kopanda RT (1976) Cocaine, kindling, and psychosis. Am J Psychiat 133:627-634.

Robinson TE, Kolb B (2004) Structural plasticity associated with exposure to drugs of abuse. Neuropharmacology 47[Suppl 1]:33-46.

Ruoslahti E (1996) RGD and other recognition sequences for integrins. Annu Rev Cell Dev Biol 12:697-715.

Schiffer WK, Liebling CN, Reiszel C, Hooker JM, Brodie JD, Dewey SL (2009) Cue-induced dopamine release predicts cocaine preference: positron emission tomography studies in freely moving rodents. J Neurosci 29:6176-6185.

Sfakianos MK, Eisman A, Gourley SL, Bradley WD, Scheetz AJ, Settleman J, Taylor JR, Greer CA, Williamson A, Koleske AJ (2007) Inhibition of Rho via Arg and p190RhoGAP in the postnatal mouse hippocampus regulates dendritic spine maturation, synapse and dendrite stability, and behavior. J Neurosci 27:10982-10992.

Shaham Y, Shalev U, Lu L, De Wit H, Stewart J (2003) The reinstatement model of drug relapse: history, methodology and major findings. Psychopharmacology (Berl) 168:3-20.

Shen HW, Toda S, Moussawi K, Bouknight A, Zahm DS, Kalivas PW (2009) Altered dendritic spine plasticity in cocaine-withdrawn rats. J Neurosci 29:2876-2884.

Shi Y, Ethell IM (2006) Integrins control dendritic spine plasticity in hippocampal neurons through NMDA receptor and Ca2+/calmodulindependent protein kinase II-mediated actin reorganization. J Neurosci 26:1813-1822.

Sutton MA, Schmidt EF, Choi KH, Schad CA, Whisler K, Simmons D, Karanian DA, Monteggia LM, Neve RL, Self DW (2003) Extinction-induced upregulation in AMPA receptors reduces cocaine-seeking behaviour. Nature 421:70-75.

Toda S, Alguacil LF, Kalivas PW (2003) Repeated cocaine administration changes the function and subcellular distribution of adenosine A1 receptor in the rat nucleus accumbens. J Neurochem 87:1478-1484.

Toda S, Shen HW, Peters J, Cagle S, Kalivas PW (2006) Cocaine increases actin cycling: effects in the reinstatement model of drug seeking. J Neurosci 26:1579-1587.

van der Flier A, Sonnenberg A (2001) Function and interactions of integrins. Cell Tissue Res 305:285-298.

Wang XB, Bozdagi O, Nikitczuk JS, Zhai ZW, Zhou Q, Huntley GW (2008) Extracellular proteolysis by matrix metalloproteinase-9 drives dendritic spine enlargement and long-term potentiation coordinately. Proc Natl Acad Sci U S A 105:19520-19525.

Weiss F, Maldonado-Vlaar CS, Parsons LH, Kerr TM, Smith DL, Ben-Shahar O (2000) Control of cocaine-seeking behavior by drug associated stimuli in rats: effects on recovery of extinguished operant-responding and extracellular dopamine levels in the amygdala and nucleus accumbens. Proc Natl Acad Sci U S A 97:4321-4326.

Wolf ME (1998) The role of excitatory amino acids in behavioral sensitization to psychomotor stimulants. Prog Neurobiol 54:679-720.

Yao WD, Gainetdinov RR, Arbuckle MI, Sotnikova TD, Cyr M, Beaulieu JM, Torres GE, Grant SG, Caron MG (2004) Identification of PSD-95 as a regulator of dopamine-mediated synaptic and behavioral plasticity. Neuron 41:625-638.

Zhang X, Lee TH, Davidson C, Lazarus C, Wetsel WC, Ellinwood EH (2007) Reversal of cocaine-induced behavioral sensitization and associated phosphorylation of the NR2B and GluR1 subunits of the NMDA and AMPA receptors. Neuropsychopharmacology 32:377-387. 